\title{
Interactions between Serotonin and Dopamine in the Control of Impulsive Choice in Rats: Therapeutic Implications for Impulse Control Disorders
}

\author{
Catharine A Winstanley*,', David EH Theobald', Jeffrey W Dalley' and Trevor W Robbins' \\ 'Department of Experimental Psychology, University of Cambridge, Cambridge, UK
}

\begin{abstract}
Forebrain serotonergic lesions attenuate the ability of $d$-amphetamine to decrease impulsivity in a delay-discounting paradigm, potentially through interactions between the serotonin $(5-\mathrm{HT})$ and dopamine (DA) systems. Nucleus accumbens (NAC) lesions increase impulsivity, but the extent to which accumbal DA is involved in regulating impulsive choice is unknown. In the current study, the effects of intra-accumbal infusions of 6-hydroxydopamine (6-OHDA) on impulsive choice were evaluated, in combination with d-amphetamine and serotonergic drugs, in order to investigate the importance of 5-HT: DA interactions in the control of impulsive behavior. Following training on a delay-discounting task, animals received intra-NAC 6-OHDA or sham surgery. Postoperatively, subjects received systemic injections of $d$-amphetamine $(0,0.3,1.0,1.5 \mathrm{mg} / \mathrm{kg})$ and the $5-\mathrm{HT}_{\text {IA }}$ receptor agonist 8-OH-DPAT $(0,0.1,0.3,1.0 \mathrm{mg} / \mathrm{kg})$. Intra- NAC 6OHDA, which reduced local DA and NA levels by $70-75 \%$, had no effect on delay-discounting, but transiently potentiated the $d$ amphetamine-induced decrease in impulsive choice. $8-\mathrm{OH}$-DPAT $(1.0 \mathrm{mg} / \mathrm{kg})$ increased impulsivity in sham-operated controls, an effect which was blocked by the 5-HTIA receptor antagonist WAY 100635. However, 8-OH-DPAT had no effect on impulsivity in 6-OHDA NAC lesioned rats. 8-OH-DPAT $(0.3 \mathrm{mg} / \mathrm{kg})$, which did not itself alter task performance, blocked the effect of $d$-amphetamine in shamoperated controls, while WAY 100635 augmented the effect of amphetamine in all subjects. In an additional experiment, intracerebroventricular administration of the selective serotonergic toxin 5,7-dihydroxytryptamine, which decreased forebrain 5-HT levels by $85-90 \%$, did not block 8-OH-DPAT's ability to increase impulsive choice. These data suggest a significant role for $5-\mathrm{HT}$ : DA interactions within the NAC in the control of impulsivity, and in the mechanism by which amphetamine decreases impulsive choice. Neuropsychopharmacology (2005) 30, 669-682, advance online publication, 26 January 2005; doi: I 0.1 038/s..npp. 1300610
\end{abstract}

Keywords: impulsivity; delay-discounting; amphetamine; 8-OH-DPAT; 6-OHDA; 5,7-DHT

\section{INTRODUCTION}

One of the key symptoms of attention-deficit hyperactivity disorder (ADHD) is a pathological increase in impulsive behavior. For example, ADHD patients choose more impulsively during delay-discounting tasks, where impulsivity is defined as the selection of a smaller immediate reward over a larger delayed reward. ADHD is often treated through administration of psychostimulant drugs such as amphetamine and methylphenidate, yet the neural and neurochemical basis underlying the decrease in impulsivity caused by these drugs, and indeed of impulse control in

\footnotetext{
*Correspondence: Dr CA Winstanley, Department of Psychiatry, University of Texas Southwestern Medical Center, 5323 Harry Hines Blvd, Dallas, TX 75390-9070, USA, Tel: I 214648 5936, Fax: I 214 648 4947, E-mail: cath.winstanley@utsouthwestern.edu

Received 24 May 2004; revised 13 September 2004; accepted 5 October 2004

Online publication: 7 October 2004 at http://www.acnp.org/citations/ NPPI00704040238/default/pdf
}

general, is not fully understood. A growing body of evidence has implicated the nucleus accumbens (NAC) in the regulation of impulsive choice. This region is a key node in the limbic corticostriatal loop, a circuit which is heavily implicated in goal-directed behavior (Mogenson et al, 1980; Alexander et al, 1990; Parkinson et al, 1999; Cardinal et al, 2002). Excitotoxic lesions of the NAC core have been shown to dramatically increase impulsivity in a delay-discounting procedure in rats (Cardinal et al, 2001). Furthermore, abnormalities in dopamine (DA) release and gene expression have been observed in the NAC of the spontaneously hypertensive rat, a potential animal model of ADHD (Papa et al, 1997, 1998, 2002; Carey et al, 1998).

A number of studies have highlighted the importance of DA within the NAC for many of the behavioral effects of amphetamine. 6-Hydroxydopamine (6-OHDA) lesions of the NAC, which markedly decrease local levels of DA and noradrenaline (NA), have been shown to block amphetamine-induced increases in locomotor activity (Kelly et al, 1975; Koob et al, 1978), amphetamine-induced 
increases in motoric impulsivity (Cole and Robbins, 1989), rate-dependent effects of amphetamine on schedule controlled behavior (Robbins et al, 1983), as well as selfadministration of amphetamine and place preference conditioned to the drug (Lyness et al, 1979; Spyraki et al, 1982). Furthermore, infusions of amphetamine directly into the NAC produce similar effects to those of systemic drug administration (Taylor and Robbins, 1984, 1986; Taylor and Horger, 1999; Pijnenburg et al, 1976; Carr and White, 1987; Burns et al, 1993). Moreover, the behavioral effects of intraaccumbal DA can resemble those observed following intraaccumbens and systemic administration of amphetamine (Cador et al, 1991; Campbell et al, 1997).

The therapeutic effect of amphetamine administration in ADHD has been largely attributed to the ability of this drug to alter dopaminergic neurotransmission (Solanto, 1998). However, amphetamine increases levels of NA and serotonin (5-HT) as well as DA (Kuczenski et al, 1987; Kuczenski and Segal, 1989, 1995; Balcioglu et al, 2003). Global 5-HT depletion, as achieved through intracerebroventricular (i.c.v.) administration of the serotonergic toxin 5,7-diyhydroxytryptamine (5,7-DHT), attenuated the ability of amphetamine to decrease impulsive choice in a delay-discounting task, particularly in more impulsive individuals (Winstanley et al, 2003). Furthermore, the DA antagonist cis-(z)-flupenthixol only blocked the antiimpulsivity effects of amphetamine in serotonergically lesioned animals and not in sham-operated controls, indicating an interaction between 5-HT and DA in mediating amphetamine's effects on impulsive choice (Winstanley et al, 2003).

8-OH-DPAT, a 5- $\mathrm{HT}_{1 \mathrm{~A}}$ receptor agonist, acutely decreases forebrain 5-HT levels via somatodendritic autoreceptors located on serotonergic cells in the raphé nuclei (Bonvento et al, 1992) and has been shown to block amphetamineinduced increases in locomotor activity (Przegalinski et al, 1997) and to attenuate the increase in DA produced by amphetamine administration (Ichikawa et al, 1995; Kuroki et al, 1996). In contrast to the effects of i.c.v. 5,7-DHT lesions (Winstanley et al, 2003, 2004), 8-OH-DPAT has previously been shown to alter delay-discounting performance (Bizot et al, 1999), although some effects have been hard to interpret (Evenden and Ryan, 1999). In addition to decreasing 5-HT release, 8-OH-DPAT alters DA levels in the prefrontal cortex (PFC), NAC, and striatum in rats, but the direction and magnitude of these effects appears to depend critically on the dose and route used (Ahlenius et al, 1990; Arborelius et al, 1993; Ichikawa et al, 1995; Ichikawa and Meltzer, 2000).

The aims of the current study were therefore to investigate the contribution of DA within the NAC to the regulation of impulsive choice through locally depleting DA within this area via infusions of 6-OHDA. Subsequently, the effects of $d$-amphetamine and 8-OH-DPAT on delaydiscounting performance were assessed in these animals as compared to sham-treated controls in order to further explore the role of 5-HT and 5-HT : DA interactions within the NAC in the control of impulsive behavior. In a subsequent experiment, the effects of 8-OH-DPAT were also determined in animals with i.c.v. 5,7-DHT lesions in order to clarify further the mechanism by which $8-\mathrm{OH}-$ DPAT may be altering impulsive choice.

\section{MATERIALS AND METHODS}

\section{Subjects}

Subjects were 34 male Lister Hooded rats (Charles River, Kent, UK) weighing $300-320 \mathrm{~g}$ at the start of each experiment. Subjects were maintained at $85 \%$ of their free-feeding weight and fed $14 \mathrm{~g}$ of food per day (inclusive of any reward they obtained during the behavioral test sessions). Animals were housed in groups of four under a reverse light cycle (lights on from 1900 to 0700 hours) and water was freely available. Testing took place between 0800 and 1900 hours 5-6 days per week. Experiments were undertaken in accordance with the UK Animals (Scientific Procedures) Act 1986.

\section{Behavioral Testing}

The behavioral apparatus and testing procedure have previously been described in detail (Winstanley et al, 2003). In brief, testing occurred in eight operant conditioning chambers (Med Associates Inc., Vermont, USA) fitted with two retractable levers located on either side of a food magazine into which $45 \mathrm{mg}$ food pellets (Noyes dustless pellets, Sandown Scientific, UK) could be delivered. The apparatus was controlled by software written in Arachnid, a real-time extension to BBC BASIC, running on Acorn Archimedes series computers (Cambridge, UK).

Subjects first learned to respond on the levers for food reward, and to nosepoke in the food magazine to trigger presentation of the levers. Animals were then trained to perform a delay-discounting task based on the original paradigm developed by Evenden and Ryan (1996). Each session lasted $100 \mathrm{~min}$, and consisted of five blocks of 12 trials, each of which lasted for $100 \mathrm{~s}$ regardless of the choice made by the subject. Each block of trials began with two forced-choice trials. The onset of the houselight signalled the beginning of each trial, whereupon the rat had to nosepoke in the food magazine in order to trigger presentation of the levers. If the rat failed to either respond at the food magazine or subsequently on the levers within $10 \mathrm{~s}$, the trial was scored as an omission, and the box returned to the inter-trial-interval (ITI) state with the houselight extinguished until the next trial was scheduled to begin. When the rat responded on one of the levers, the houselight was turned off and the levers retracted. For each rat, responding on one lever (lever A) always provided a small immediate reward of one pellet, the other (lever B) a large reward of four pellets. The location of levers $A$ and $B$ were counterbalanced between subjects. As the session progressed, the delay to the large reward was increased in each block of trials in a step-wise fashion, from 0 to 10,20 , 40 , and then $60 \mathrm{~s}$. Onset of the traylight signalled delivery of food, after which the box returned to the ITI state. Training continued over 36 sessions until stable baseline behavior was achieved.

\section{Experiment 1}

Surgery. A detailed description of the surgical procedure has been provided previously (Dalley et al, 2002). In brief, subjects were matched for baseline performance and divided into two groups. Animals were anaesthetized with 
ketamine (Ketaset, $100 \mathrm{mg} / \mathrm{kg}$ i.m.; Vet Drug, Bury St Edmunds, UK) and xylazine (Rompun, $10 \mathrm{mg} / \mathrm{kg}$ i.m.; Vet Drug). Subjects received bilateral intraccumbal infusions of either vehicle $(0.2 \mathrm{mg} / \mathrm{ml} \mathrm{L}$-ascorbic acid in $0.9 \%$ saline; $n=8$ ) or 6-OHDA ( $8 \mathrm{mg} / \mathrm{ml}$ free base; Sigma, UK) dissolved in vehicle $(n=10)$ at the following stereotaxic coordinates: $\mathrm{AP}+3.4$ from bregma, $L \pm 1.7$ from the midline, $\mathrm{DV}:-7.2$ from dura). The incisor bar was set at +5.5 relative to intra-aural zero. In total, $1 \mu$ l of solution was infused over 2 min (total amount of 6 -OHDA infused per side $=8 \mu \mathrm{g}$ ). Subsequent to the completion of the surgical procedure, animals had free access to food and water in their home cages for 7 days prior to retesting on the delay-discounting task.

Experiment 1.1: Effect of d-amphetamine on delaydiscounting performance in both sham-operated and 6-OHDA NAC lesioned rats. For consistency, the drug regimen was based on that utilized in previous experiments using this behavioral paradigm (Cardinal et al, 2000; Winstanley et al, 2003), and began following collection of postoperative baseline data necessary for analysis of the lesion. Injections were given in sets of 6 consecutive days in the following order: saline, $0.3 \mathrm{mg} / \mathrm{kg}$ amphetamine, saline, $1.0 \mathrm{mg} / \mathrm{kg}$ amphetamine, saline, $1.5 \mathrm{mg} / \mathrm{kg}$ amphetamine. This dose regimen was repeated twice to check for any changes in the response to amphetamine over time, with a 10-day washout period between each replication during which time animals were tested every other day. The study took 3 weeks in total. Each rat received the same drug on the same days. Repeated saline injections were included in the drug design so that the effect of each injection could be compared against the immediately preceding vehicle session so as to increase the power for detecting drug effects with gradually shifting baselines.

Experiment 1.2: Effect of the 5-HT $\mathrm{T}_{1 \mathrm{~A}}$ receptor agonist 8-OH-DPAT on delay-discounting performance in both sham-operated and 6-OHDA NAC lesioned rats. One week passed between the completion of experiment 1.1 and the beginning of experiment 1.2 during which time animals were tested every other day. Three doses of 8 -OH-DPAT $(0.1,0.3$, and $1.0 \mathrm{mg} / \mathrm{kg}$ i.p.) plus vehicle were administered 15 min before the task began according to a Latin square drug design. In order to ascertain whether the effects of $8-\mathrm{OH}-\mathrm{DPAT}$ were due to activation of $5-\mathrm{HT}_{1 \mathrm{~A}}$ receptors, injections of $1.0 \mathrm{mg} / \mathrm{kg} 8-\mathrm{OH}-\mathrm{DPAT}$ and of vehicle were repeated, preceded $10 \mathrm{~min}$ earlier by an injection of the selective $5-\mathrm{HT}_{1 \mathrm{~A}}$ receptor antagonist WAY $100635(0.1 \mathrm{mg} /$ $\mathrm{kg}$ s.c.), according to a counter-balanced design. Animals received injections of drug on Tuesday and Friday, and were tested without drug on Monday and Thursday.

Experiment 1.3: Effect of combined administration of d-amphetamine and 8-OH-DPAT or WAY 100635 on delay-discounting performance in both sham-operated and 6-OHDA NAC lesioned rats. One week passed between the completion of experiment 1.2 and the beginning of experiment 1.3 during which time animals were tested every other day. The three doses of amphetamine used in experiment $1.1(0.3,1.0,1.5 \mathrm{mg} / \mathrm{kg}$ i.p. $)$ plus vehicle were administered $10 \mathrm{~min}$ before the start of the task according to a Latin square drug design. On each test day, $15 \mathrm{~min}$ before the injection of amphetamine or saline was given, an intraperitoneal injection of $0.3 \mathrm{mg} / \mathrm{kg} 8-\mathrm{OH}-\mathrm{DPAT}$ was administered. A week after the end of this study, during which time animals were tested every other day, the effects of coadministration of WAY $100635(0,0.1 \mathrm{mg} / \mathrm{kg}$ s.c.) and amphetamine $(1.5 \mathrm{mg} / \mathrm{kg}$ i.p.) were evaluated according to a crossover design. Again, WAY 100635 was administered $15 \mathrm{~min}$ prior to the amphetamine injection. Animals received injections of drug on Tuesday and Friday, and were tested without drug on Monday and Thursday. Animals remained in their home cages on all other days.

Experiment 1.4: Effect of administration of amphetamine and apomorphine on locomotor activity in both sham-operated and 6-OHDA NAC lesioned rats. One week passed between the completion of experiment 1.3 and the beginning of experiment 1.4. Locomotor activity was assessed in individual activity cages over $2 \mathrm{~h}$ at approximately the same time each day. A total of 12 activity cages $(25 \times 40 \times 18 \mathrm{~cm})$ were used, each with two photocell beams located $1 \mathrm{~cm}$ above the floor and spaced equally along the length of the cage. A 'run' was scored if the two beams were broken within $0.2 \mathrm{~s}$. The data were collated over $5 \mathrm{~min}$ bins using software running on an Acorn Archimedes series computer (Cambridge, UK). Following two habituation sessions, animals were given apomorphine $(0.03$ or $0.1 \mathrm{mg} / \mathrm{kg}$, s.c.) or saline according to a Latin square design. After 1 week, animals received either amphetamine $(0.3$ or $1.5 \mathrm{mg} / \mathrm{kg}$ i.p.) or saline according to a Latin square design. Drugs were given every other day. In-between test days, the animals remained in their home cages.

In total, the behavioral testing for experiment 1 took approximately 4 months to complete after surgery.

\section{Experiment 2}

Surgery. A detailed description of the surgical procedure has been previously published (Winstanley et al, 2003). In brief, subjects were matched for baseline performance and divided into two equal groups $(n=8)$, one of which received i.c.v. 5,7-DHT lesions, the other corresponding sham surgery, under Avertin anaesthesia (10 g 2,2,2-tribromoethanol (Fluka, Germany) in $5 \mathrm{~g}$ tertiary amyl alcohol, diluted in a solution of $40 \mathrm{ml}$ ethanol and $450 \mathrm{ml}$ phosphatebuffered saline (PBS)) using standard stereotaxic techniques. All rats were treated $30 \mathrm{~min}$ before the start of surgery with $15 \mathrm{mg} / \mathrm{kg}$ desmethylimipramine $\mathrm{HCl}$ (Sigma, UK) dissolved in double distilled water to protect noradrenergic neurons from the neurotoxin. After surgery, animals had free access to food and water in their home cages for 10 days prior to retraining on the delay-discounting task to allow for the degeneration of 5-HT-containing neurons (Bjorkland et al, 1975).

Experiment 2.1: Effect of 8-OH-DPAT on delaydiscounting performance in both sham-operated and i.c.v. 5,7-DHT lesioned rats. The drug regimen began following collection of postoperative baseline data necessary for analysis of the lesion. Three doses of 8-OH-DPAT (0.1, 
0.3 and $1.0 \mathrm{mg} / \mathrm{kg} \mathrm{IP}$ ) plus vehicle were administered $15 \mathrm{~min}$ before the task began according to a Latin square drug design.

Ex vivo lesion analysis. The day after the final drug injections, all subjects were killed through exposure to increasing concentrations of carbon dioxide. A detailed description of the ex vivo analysis procedure has been provided previously (Dalley et al, 2002, Winstanley et al, 2003). In brief, the brains were rapidly removed and frozen on dry ice. Samples of tissue ( $\sim 0.4 \mathrm{mg}$ ) from discrete brain regions were obtained using a micropunch from coronal slices $(150 \mu \mathrm{m}$ thickness) cut on a cryostat. Levels of DA, 5-HT, and their metabolites dihydroxyphenylacetic acid (DOPAC) and 5-hydroxyindoleacetic acid (5-HIAA), and NA were determined in samples of brain tissue taken from discrete regions by reversed phase high-performance liquid chromatography (HPLC).

Drugs. All drugs were made up fresh on each test day and were obtained from Sigma (UK). Both $d$-amphetamine sulfate and 8-OH-DPAT were dissolved in sterile $0.9 \%$ saline. All doses were calculated as the salt. WAY 100635 was dissolved in $0.01 \mathrm{M}$ PBS. Doses were calculated as the free base. All drug injections were given in a different location from the testing room and the room where the animals were housed.

Data analyses. All analyses were conducted using SPSS for Windows (version 9.0; SPSS, Chicago, IL, USA). The total number of choices of the large reward during each delay per session was used to analyze choice behavior. The number of omissions made did not affect this choice measure. These data were subjected to an arcsine transformation in order to limit the effect of an artificially imposed ceiling (10 responses per delay was the maximum possible per session). In order to judge whether an animal had successfully acquired the task and reached stable baseline performance, data from 10 sessions were analyzed by repeated-measures ANOVA with two within-subjects factors, DAY and DELAY. In order to satisfy performance criteria, the effect of DELAY had to be significant at the $p<0.05$ level and the effect of DAY nonsignificant, that is, performance had to be delaydependent and stable over 10 sessions, regardless of the pattern of choice shown.

Once stable behavior had been attained, the individual variation within the subject group was analyzed through fitting an exponential curve to data from individual subjects of the form:

$$
y=\mathrm{e}^{-(k d)}
$$

where $y=$ number of choices of the large reward, $d=$ delay to the large reward.

The coefficient $k$ determined the rate of exponential decay of choice of the larger delayed reward with time. Subjects were matched for baseline performance using the $k$ values so that the same range of behavioral variation was present in both sham and lesioned animals (for more detail, see Winstanley et al, 2003).

The effects of the neurotoxic lesions were assessed through comparison of data collected over the final seven preoperative sessions and the first seven postoperative sessions. Data were analyzed using a repeated measures ANOVA with SURGERY (two levels, pre-op and post-op), DAY and DELAY as within-subjects factors. The post-op data were also subjected to a repeated-measures ANOVA with DAY and DELAY as within-subjects factors and LESION as a between-subjects factor. In addition to the number of choices of the large reward made per delay, the total number of omissions made per session and the average time taken to respond on either lever (response latency) per session were also analyzed.

Data from drug studies were analyzed by repeatedmeasures ANOVA, with DRUG and DELAY as withinsubjects factors and LESION as a between-subjects factor. Owing to repeated administration of amphetamine, a further ANOVA was performed on data from the two courses of administration, with REPLICATION, DOSE, and DELAY as within-subjects factors and LESION as a between-subjects factor. For each course of drug injections, the average response to the saline injection for that round was calculated and entered into the ANOVA. If there was a significant main effect of DOSE, that dose of amphetamine was compared against the vehicle injection which directly preceded it. In order to assess whether WAY 100635 had blocked the effect of 8-OH-DPAT, the effect of 8-OH-DPAT alone was compared to the effect of 8-OH-DPAT plus WAY 100635. Data were analyzed by repeated-measures ANOVA as before with ANTAGONIST (two levels: present or absent), DOSE, and DELAY as within-subjects factors and LESION as a between-subjects factor.

Similarly, in order to assess any interactions between 8OH-DPAT or WAY 100635 and amphetamine, the effect of amphetamine alone was compared to the effect of amphetamine plus each serotonergic drug. Data were analyzed by repeated-measures ANOVA as before with AGONIST (in the case of 8-OH-DPAT) or ANTAGONIST (in the case of WAY 100635) as a within-subjects factor with two levels (present or absent). DOSE and DELAY were also included as within-subjects factors, and LESION as a between-subjects factor. Significant DOSE $\times$ DELAY and DOSE $\times$ DELAY $\times$ LESION effects were followed up using either further ANOVA examining responses to single drug doses over delay, or paired-sample $t$-tests comparing either sham and lesion data or vehicle and drug data at different delays.

Locomotor activity data were analyzed by repeated measures ANOVA with BIN as a within-subjects factor and LESION as a between-subjects factors. The effects of amphetamine and apomorphine were also determined by repeated-measures ANOVA, with DOSE and BIN as withinsubjects factors and LESION as a between-subjects factors. If a main effect of DOSE was observed, a further ANOVA was performed of similar design comparing each dose of drug to saline.

\section{RESULTS}

\section{Experiment 1}

Lesion assessment. As shown in Table 1, levels of DA and NA were markedly reduced within the NAC of rats with 6-OHDA lesions as compared to sham-operated controls 
Table I Tissue Concentrations of 5-HT, 5-HIAA, DA, DOPAC, and NA in Cortical and Striatal Areas of NAC 6-OHDA Lesioned and Sham-Operated Rats

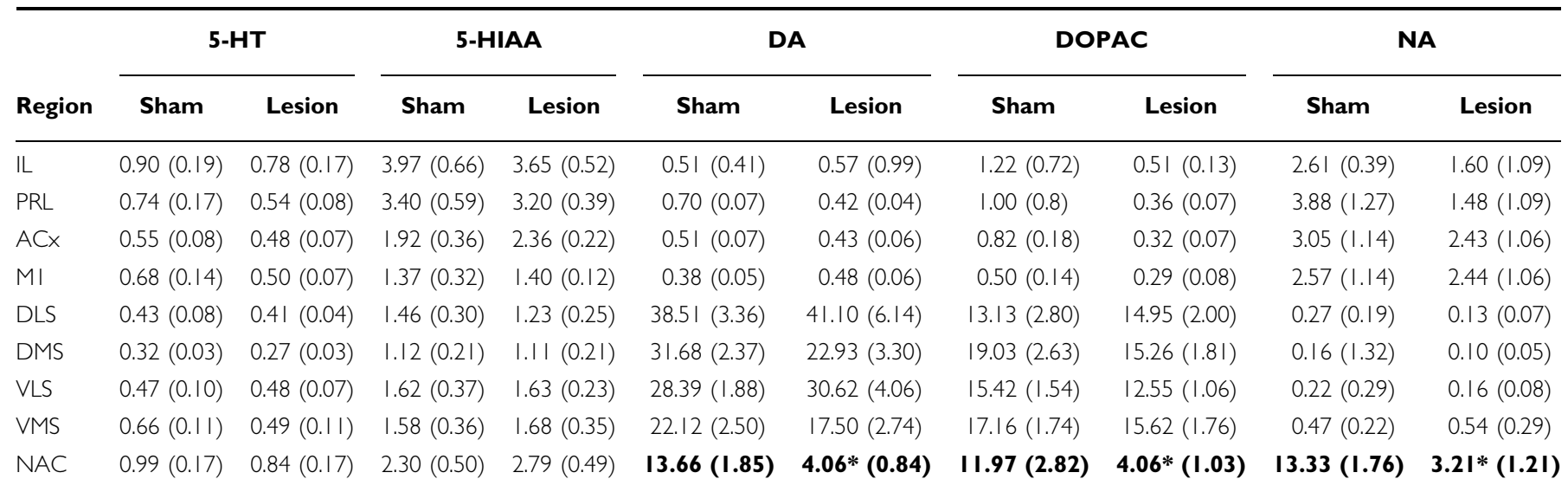

The data are averaged levels ( \pm SEM) expressed as pmol/mg to two decimal places. Levels of accumbal DA, DOPAC and NA are highlighted in bold. *Indicates a significant difference $(p<0.05)$ between sham and lesioned groups.

IL, infralimbic cortex; PRL, prelimbic cortex; Acx, anterior cingulate cortex; MI, primary motor area; DLS, dorsolateral striatum; DMS, dorsomedial striatum; VLS, ventrolateral striatum; VMS, ventromedial striatum; NAC, nucleus accumbens.

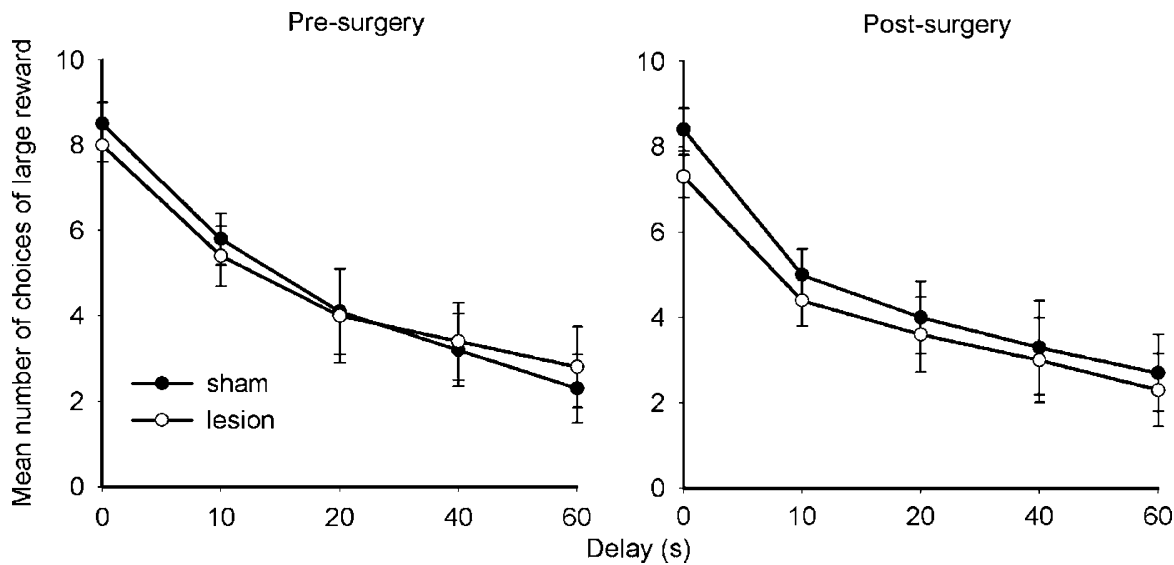

Figure I Lack of effect of 6-OHDA lesions of the NAC on delay-discounting performance. Data shown are mean and SEM from seven stable postoperative sessions.

(DA: 70.3\%; NA: $75.9 \%$ ), but not in surrounding brain areas. Levels of NA also appeared to be slightly lower in the frontal cortex of NAC 6-OHDA lesioned rats, yet these differences did not reach statistical significance. This level of depletion is typical of that found with this lesion protocol (eg Dalley et al, 2002; Richards et al, 2002), and allows valid comparisons to be made between this study and others that have used similar methodology. Levels of 5-HT and 5-HIAA were unaffected by the 6-OHDA lesion in any brain region tested.

Effect of 6-OHDA NAC lesions on delay-discounting performance. 6-OHDA lesions of the NAC had no effect on impulsive choice (Figure 1), as indicated by the absence of a significant difference in postoperative performance between sham and lesioned groups (LESION: $\mathrm{F}_{1,16}=0.059$ NS, LESION $\times$ DELAY: $\quad F_{4,6}=0.481, \quad$ NS). Performance following surgery was not significantly different from that preceding surgery, as indicated by nonsignificant effects of
SURGERY $\quad\left(\mathrm{F}_{1,14}=0.483, \quad \mathrm{NS}\right) \quad$ or $\quad$ SURGERY $\times$ LESION interactions $\left(\mathrm{F}_{1,14}=1.400, \mathrm{NS}\right)$. In addition, animals with 6-OHDA lesions made a similar numbers of omissions (LESION: $\mathrm{F}_{1,16}=3.007, \mathrm{NS}$ ), and were just as fast to make a correct response (LESION: $\mathrm{F}_{1,16}=3.453$, NS) or collect food reward (LESION: $\mathrm{F}_{1,16}=1.393$, NS) as sham-operated controls (see Table 2). Although the mean data values indicate that the lesioned animals were slightly faster to make these responses, these differences were not significant.

Effect of d-amphetamine on delay-discounting performance. Considering the data averaged over both courses of drug administration, amphetamine significantly increased choice of the large reward across delay (DOSE $\times$ DELAY: $\mathrm{F}_{12,192}=1.952, p<0.031$; Figure 2 ). The ability of amphetamine to alter choice behavior was evident in both sham-operated and lesioned animals, as evidenced by nonsignificant DOSE $\times$ LESION $\left(\mathrm{F}_{1,1}=0.254\right.$, NS $)$ or DOSE $\times$ $\mathrm{DELAY} \times$ LESION terms $\left(\mathrm{F}_{1,1}=1.296\right.$, NS $)$. However, when 


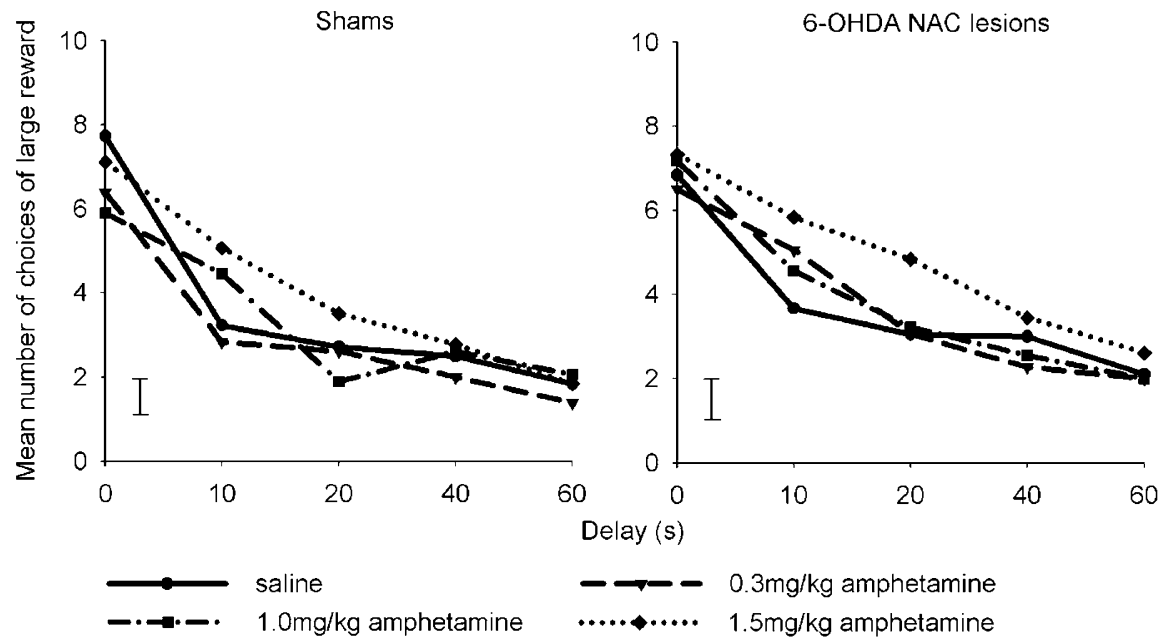

Figure 2 Effects of amphetamine (0, 0.3, 1.0, $1.5 \mathrm{mg} / \mathrm{kg}$ i.p.) on delay-discounting performance in rats with 6-OHDA lesions of the NAC and shamoperated controls. Data shown are the population mean and SED of choice behavior averaged over both rounds of administration. The average response to the saline injections administered in each round was calculated, and then these data were pooled.
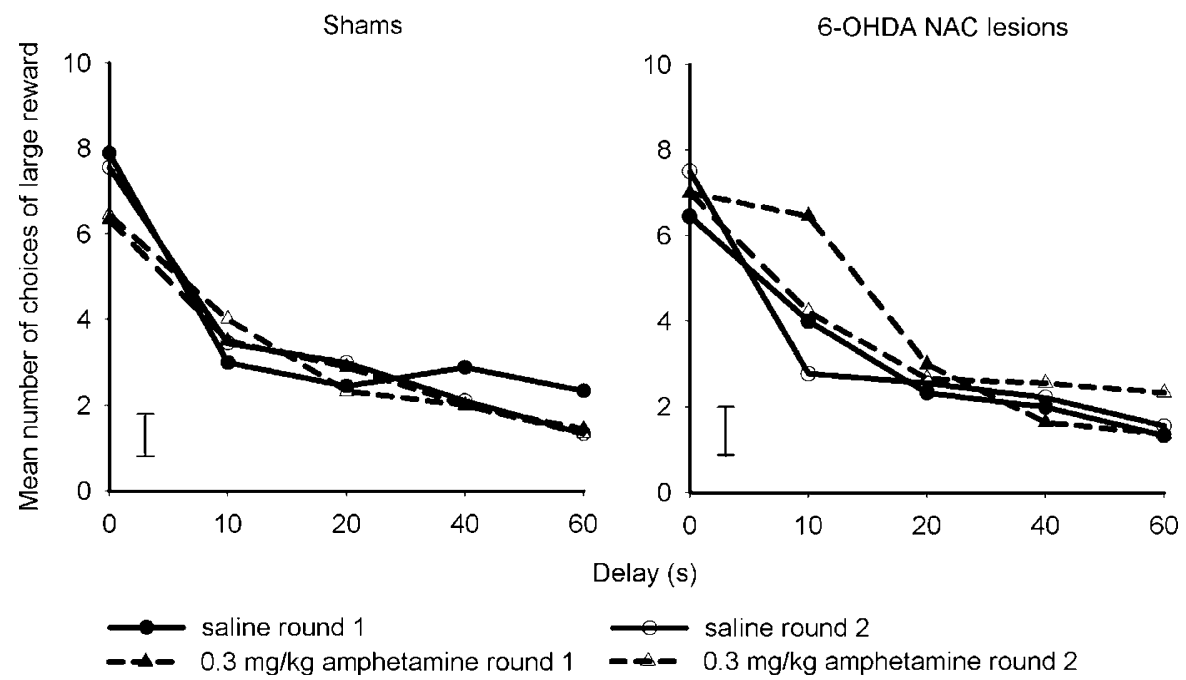

elay (s)

saline round 2

- $0.3 \mathrm{mg} / \mathrm{kg}$ amphetamine round 2

Figure 3 Effects of amphetamine (0, $0.3 \mathrm{mg} / \mathrm{kg}$ i.p.) in course I and course 2 on delay-discounting performance in rats with 6-OHDA NAC lesions and sham-operated controls. Data shown are mean and SED.

the two courses of drug injections were compared, there was a significant REPLICATION $\times$ DOSE interaction $\left(\mathrm{F}_{3,48}=\right.$ $3.560, p<0.021)$, suggesting that the response to one or more of the drug doses altered between the first and second courses of amphetamine administration. The response to the saline injections did not vary significantly (INJECTION: $\mathrm{F}_{5,80}=1.516$, NS).

When the effects of each dose were analyzed separately against saline, a significant REPLICATION $\times$ DOSE $\times$ DELAY effect was observed with the lowest dose of amphetamine used $\left(\mathrm{F}_{4,64}=4.096, p<0.005\right.$, Figure 3$)$. Further statistical analysis revealed that the lesioned animals appeared to be more sensitive to the effects of $0.3 \mathrm{mg} / \mathrm{kg}$ amphetamine after the first administration $\left(\right.$ DRUG $\times$ DELAY $\times$ LESION: $\left.\quad F_{12,192}=2.120, \quad p<0.026\right)$. However, when the amphetamine injections were repeated, no significant differences were observed in the response to amphetamine between sham-operated and lesioned subjects
Table 2 The Average Number of Trials Omitted, the Latency to Make a Response, and the Latency to Collect Reward in Subjects with 6-OHDA Lesions of the NAC and Sham-Operated Controls

\begin{tabular}{lll}
\hline & Sham & Lesion \\
\hline Omissions & $1.14(0.16)$ & $0.33(0.13)$ \\
Response latency (s) & $1.02(0.01)$ & $0.81(0.02)$ \\
Collection latency (s) & $0.38(0.01)$ & $0.30(0.01)$ \\
\hline
\end{tabular}

Data shown are mean (SEM) over seven postoperative sessions.

$\left(\right.$ DRUG $\times$ DELAY $\times$ LESION: $\left.F_{12,192}=0.357, N S\right)$. In accordance with previous results (Winstanley et al, 2003), administration of these doses of amphetamine did not affect the number of trials omitted (DOSE: $\mathrm{F}_{3,45}=1.450$, NS), the latency to respond (DOSE: $F_{3,45}=2.180, N S$ ) or the 
latency to collect reward (DOSE: $\mathrm{F}_{3,45}=0.920$, NS; data not shown, see Table 2 for baseline values).

Effect of 8-OH-DPAT on delay-discounting performance. The 5- $\mathrm{HT}_{1 \mathrm{~A}}$ receptor agonist 8-OH-DPAT had the opposite effect to amphetamine, increasing choice of the small immediate reward across delay at the highest dose $\left(\right.$ DOSE $\times$ DELAY: $\mathrm{F}_{12,180}=16.481, p<0.0001 ; 1.0 \mathrm{mg} / \mathrm{kg} v s$ vehicle: DOSE $\times$ DELAY: $\mathrm{F}_{4,60}=2.656, p<0.041$, Figure 4 ). However, this effect was completely blocked in animals with 6-OHDA NAC lesions (DOSE $\times$ DELAY $\times$ LESION: $\mathrm{F}_{12,180}=1.892, \quad p<0.038 ; 1.0 \mathrm{mg} / \mathrm{kg} \quad v s$ vehicle: DOSE $\times$ DELAY $\times$ LESION: $\left.F_{12,60}=4.528, p<0.003\right) .8$-OH-DPAT did not affect the number of trials omitted (DOSE: $\mathrm{F}_{3,45}=$ 1.783 , NS), hence subjects were still motivated to earn reinforcement. The latency to respond and the latency to collect reward were also unaffected by the drug (response latency: DOSE: $\mathrm{F}_{3,45}=1.857$, NS; collection latency: DOSE: $\mathrm{F}_{3,45}=1.900$, NS; data not shown, see Table 2 for baseline values). Furthermore, the effect of 8-OH-DPAT to increase impulsive choice in sham animals was blocked by prior administration of the $5-\mathrm{HT}_{1 \mathrm{~A}}$ receptor antagonist WAY 100635 (ANTAGONIST: $\mathrm{F}_{1,8}=6.906, p<0.03$ ), indicating that the change in behavior observed following 8-OH-DPAT injections can be attributed to its action at $5-\mathrm{HT}_{1 \mathrm{~A}}$ receptors. WAY 100,635 had no effect on behavior when administered alone in either sham-operated or lesioned animals (DOSE: $F_{1,15}=1.143$, NS; DOSE $\times$ LESION: $F_{1,15}$ $<1, \mathrm{NS})$.

Effect of coadministration of 8-OH-DPAT and d-amphetamine on delay-discounting performance. The highest dose of 8-OH-DPAT, which did not affect choice behavior $(0.3 \mathrm{mg} / \mathrm{kg})$, was selected for use in this part of the study. In addition, it is comparable to the dose used in a previous study to investigate the effects of $5-\mathrm{HT}_{1 \mathrm{~A}}$ receptor stimulation on cocaine-induced hypermotility (De La Garza and
Cunningham, 2000). A significant AGONIST $\times$ DOSE interaction was observed, indicating that coadministration of the $5-\mathrm{HT}_{1 \mathrm{~A}}$ receptor agonist was altering the response profile to amphetamine (AGONIST $\times$ DOSE: $\mathrm{F}_{3,45}=4.353, p<0.009$, Figure 5). However, there were significant differences between sham-operated and lesioned subjects in their response to coadministration of the drugs (AGONIST $\times$ DELAY $\times$ LESION: $\left.F_{4,60}=3.456, p<0.025\right)$. In shamoperated animals, prior administration of 8-OH-DPAT blocked the ability of amphetamine to increase choice of the large reward (AGONIST $\times$ DOSE: $F_{3,24}=3.123$, $p<0.045)$. When only the data from the coadministration of 8-OH-DPAT and amphetamine were analyzed, there was no longer a significant delay-dependent effect of amphetamine (DOSE $\times$ DELAY: $\mathrm{F}_{12,96}=0.932$, NS). In the lesioned animals, the ability of 8-OH-DPAT to block the effect of amphetamine was still evident (AGONIST $\times$ DOSE $\times$ DELAY: $\left.\mathrm{F}_{12,84}=2.161, p<0.021\right)$, but when the data from the coadministration of 8-OH-DPAT and amphetamine were analyzed alone, a significant delay-dependent effect of amphetamine was nevertheless still observed (DOSE $\times$ DELAY: $\left.\quad \mathrm{F}_{12,96}=2.610, \quad p<0.015\right)$. Coadministration of 8-OH-DPAT and amphetamine did not affect the number of omissions made (AGONIST $\times$ DOSE: $\mathrm{F}_{3,45}=0.276$, NS), the latency to make a response (AGONIST $\times$ DOSE: $\mathrm{F}_{3,45}=0.422$, NS), or the latency to collect reward $\left(\right.$ AGONIST $\times$ DOSE: $\mathrm{F}_{3,45}=0.046$, NS; data not shown, see Table 2 for baseline values).

To summarize, systemic 8-OH-DPAT completely blocked the ability of amphetamine to decrease impulsive choice in sham-operated animals, but the 8-OH-DPAT-induced blockade of amphetamine's effects was only partial in animals with 6-OHDA NAC lesions.

Effect of coadministration of WAY 100635 and amphetamine on delay-discounting performance. The same dose of WAY 100635 was used in this part of the experiment as in

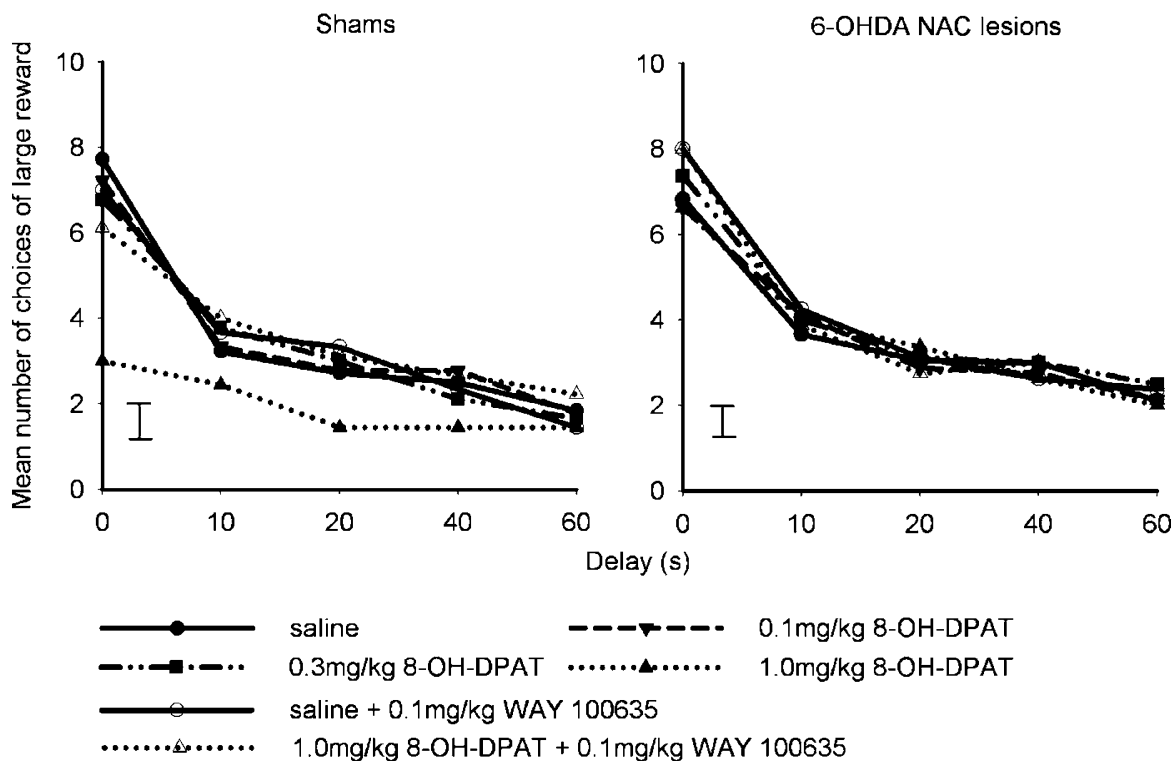

Figure 4 Effects of administration of the $5-\mathrm{HT}_{\text {IA }}$ receptor agonist $8-\mathrm{OH}-\mathrm{DPAT}(0,0.1,0.3,1.0 \mathrm{mg} / \mathrm{kg}$ i.p.), and coadministration with the 5- $\mathrm{HT}$ ।A receptor antagonist WAY 100635 (0.1 mg/kg s.c.) on delay-discounting performance in rats with 6-OHDA lesions of the NAC and sham-operated controls. Data shown are mean and SED. 


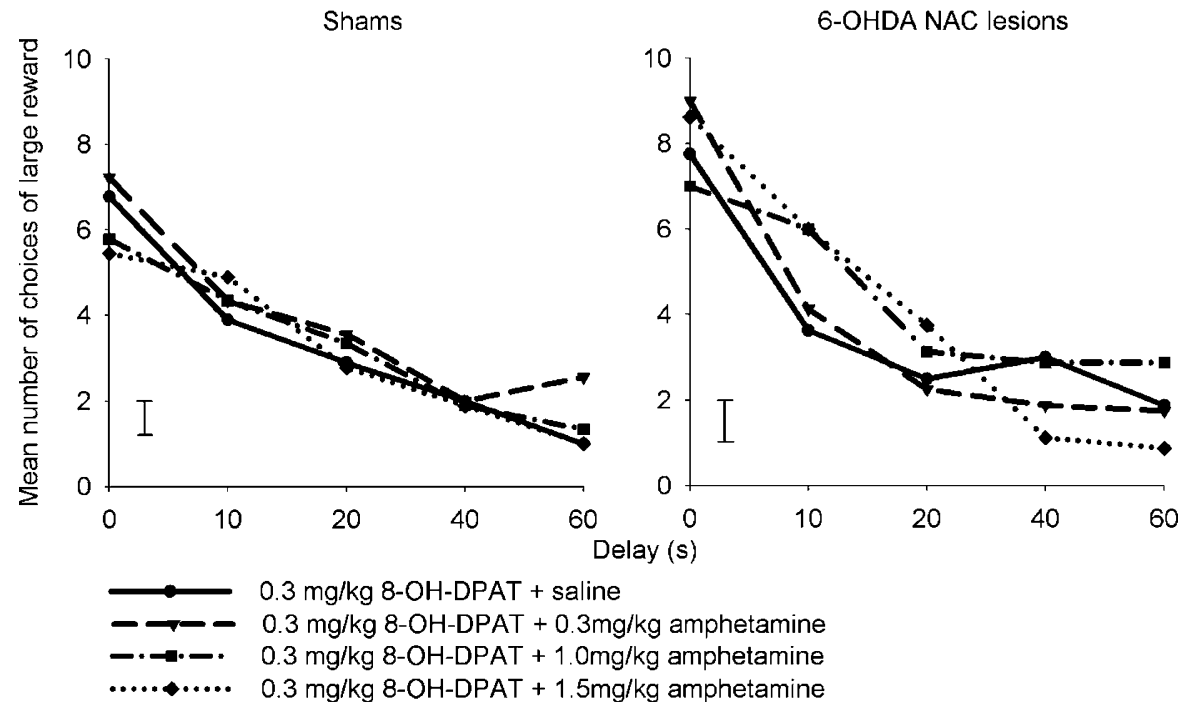

Figure 5 Effects of coadministration of the $5-\mathrm{HT}_{\text {IA }}$ receptor agonist $8-\mathrm{OH}-\mathrm{DPAT}(0.3 \mathrm{mg} / \mathrm{kg}$ i.p.) and amphetamine $(0,0.3,1.0,1.5 \mathrm{mg} / \mathrm{kg}$ i.p. $)$ on delaydiscounting performance in rats with 6-OHDA lesions of the NAC and sham-operated controls. Data shown are mean and SED.

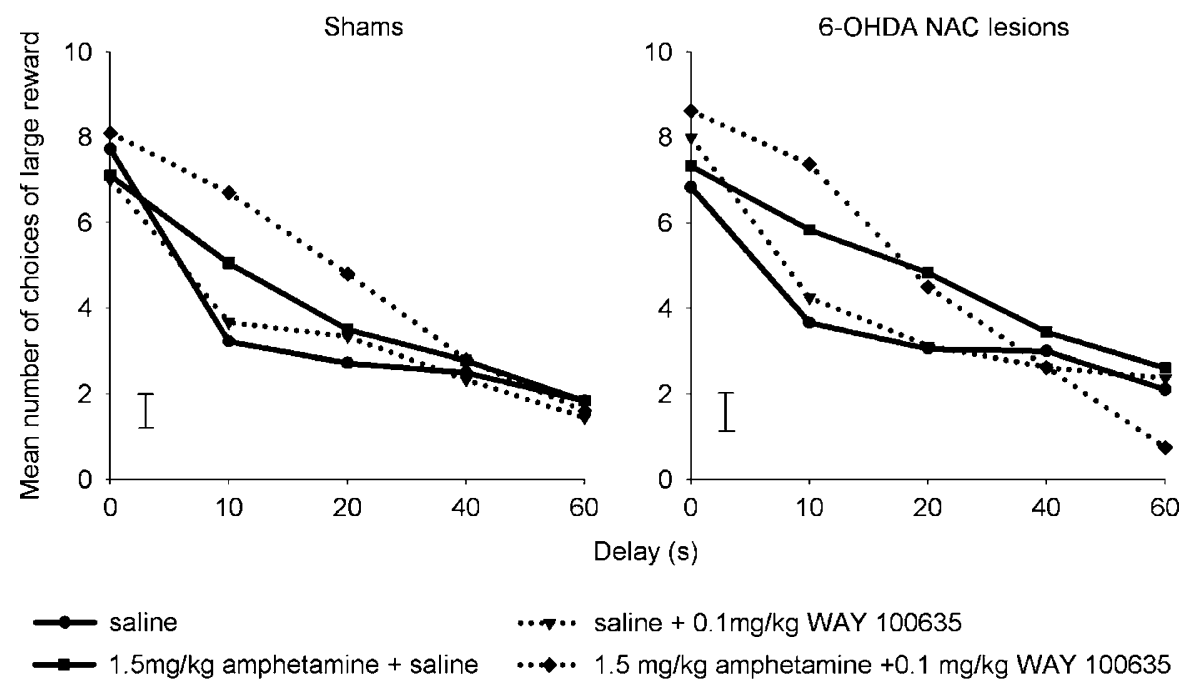

Figure 6 Effects of coadministration of the 5-HT IA receptor antagonist WAY 100635 (0, 0.1 mg/ $/ \mathrm{kg}$ s.c.) and amphetamine (0, I.5 mg/kg i.p.) on delaydiscounting performance in rats with 6-OHDA lesions of the NAC and sham-operated controls. Data shown are mean and SED.

experiment 1.3, as it had no effect on delay-discounting performance. Only the highest dose of amphetamine was tested in combination with WAY 100635. The decrease in impulsive choice observed following amphetamine administration was similar to that observed in experiment 1.1 (REPETITION: $\mathrm{F}_{1,18}<1$, NS). Comparing the effects of amphetamine alone with those observed following WAY 100635 plus amphetamine, a significant main effect of ANTAGONIST was observed $\left(\mathrm{F}_{1,15}=13.967, p<0.002\right.$, Figure 6). The coadministration of the $5-\mathrm{HT}_{1 \mathrm{~A}}$ receptor antagonist had the opposite effect to coadministration of the $5-\mathrm{HT}_{1 \mathrm{~A}}$ receptor agonist $8-\mathrm{OH}-\mathrm{DPAT}$ in that it appeared to augment the ability of amphetamine to increase choice of the large reward (ANTAGONIST $\times$ DRUG $\times$ DELAY: $\left.\mathrm{F}_{4,60}=9.109, p<0.009\right)$. These effects of WAY 100635 were particularly pronounced when the delay to the large reward were short (10 s: ANTAGONIST: $\mathrm{F}_{1,15}=4.451, p<0.035$ ) but were no longer evident at the longer delays $(60 \mathrm{~s}$ : ANTAGONIST: $F_{1,15}=1.656$, NS). Furthermore, this effect was present in both sham and lesioned animals (ANTAGONIST $\times$ LESION: $\mathrm{F}_{4,60}<1$, NS; ANTAGONIST $\times$ DRUG $\times$ DELAY $\times$ LESION: $\mathrm{F}_{4,60}=1.292$, NS). As the selective $5-\mathrm{HT}_{1 \mathrm{~A}}$ receptor antagonist WAY 100635 had such pronounced effects on the ability of amphetamine to modify choice behavior, attempting to block the effects of 8-OH-DPAT using this dose of WAY 100635 did not seem to be a valid approach.

Coadministration of WAY 100635 and amphetamine did not affect the number of omissions made (ANTAGONIST: $\mathrm{F}_{4,60}=0.394$, NS), the latency to make a response (ANTAGONIST: $\mathrm{F}_{4,60}=1.550$, NS), or the latency to collect reward (ANTAGONIST: $\mathrm{F}_{4,60}=0.792$, NS) (data not shown, see Table 2 for baseline values). 
Effect of 6-OHDA NAC lesions on locomotor activity. Animals with 6-OHDA NAC lesions showed higher levels of spontaneous locomotor activity (LESION: $\mathrm{F}_{1,14}=10.366$, $p<0.007$, Figure 7). Apomorphine significantly increased locomotor behavior at the highest dose given (DOSE: $\mathrm{F}_{2,26}=14.126, p<0.002 ; 0.1 \mathrm{mg} / \mathrm{kg}$ vs saline: $\mathrm{F}_{1,13}=25.100$, $p<0.0001)$ in both sham and lesioned animals. Administration of $0.03 \mathrm{mg} / \mathrm{kg}$ apomorphine did not significantly alter locomotor activity in either group (DOSE: $\mathrm{F}_{1,13}=$ 0.568 , NS). A similar pattern of effects was observed when the data were transformed into the percentage change in activity from baseline levels, in that the lower dose has no effect (DOSE: $\mathrm{F}_{2,26}=8.370, p<0.004 ; 0.3 \mathrm{mg} / \mathrm{kg} v s$ saline: DOSE: $\mathrm{F}_{1,13}=0.266$, NS), whereas the higher dose significantly increased activity (DOSE: $\mathrm{F}_{1,13}=23.680, p<0.0001$ ). However, in terms of changes from baseline performance, the increase in activity was significantly greater in shamoperated animals compared to those with 6-OHDA NAC lesions (DOSE $\times$ LESION $\mathrm{F}_{1,13}=4.029, p<0.041 ;$ DOSE $\times$ LESION: $\left.\mathrm{F}_{1,13}=4.938, p<0.045\right)$.

Both 0.3 and $1.5 \mathrm{mg} / \mathrm{kg}$ amphetamine increased locomotor activity in keeping with previous reports (DOSE: $\mathrm{F}_{2,26}=217.94, \quad p<0.001 ; 0.3 \mathrm{mg} / \mathrm{kg}, \quad$ DOSE: $\mathrm{F}_{1,13}=85.76$, $p<0.001 ; 1.5 \mathrm{mg} / \mathrm{kg}$, DOSE: $\left.\mathrm{F}_{1,13}=310.71, p<0.001\right)$. However, at the highest dose tested, the increase in activity was significantly more pronounced in sham-operated animals (DOSE $\times$ LESION: $\mathrm{F}_{2,26}=8.855, p<0.003,0.3 \mathrm{mg} / \mathrm{kg}$ DOSE $\times$ LESION $=\mathrm{F}_{1,13}=1.465, \quad \mathrm{NS} ; \quad 1.5 \mathrm{mg} / \mathrm{kg}: \quad \mathrm{F}_{1,13}=7.287$, $p<0.02)$. This difference can be seen more clearly when plotting the data as the percentage change in activity from baseline levels (DOSE $\times$ LESION: $F_{2,26}=5.237, p<0.012$; $0.3 \mathrm{mg} / \mathrm{kg}$ DOSE $\times$ LESION; $\mathrm{F}_{1,13}=0.019, \quad \mathrm{NS} ; 1.5 \mathrm{mg} / \mathrm{kg}$ : $\left.\mathrm{F}_{1,13}=4.417, p<0.046\right)$. However, analyzing the change in locomotor activity as a percentage change from baseline
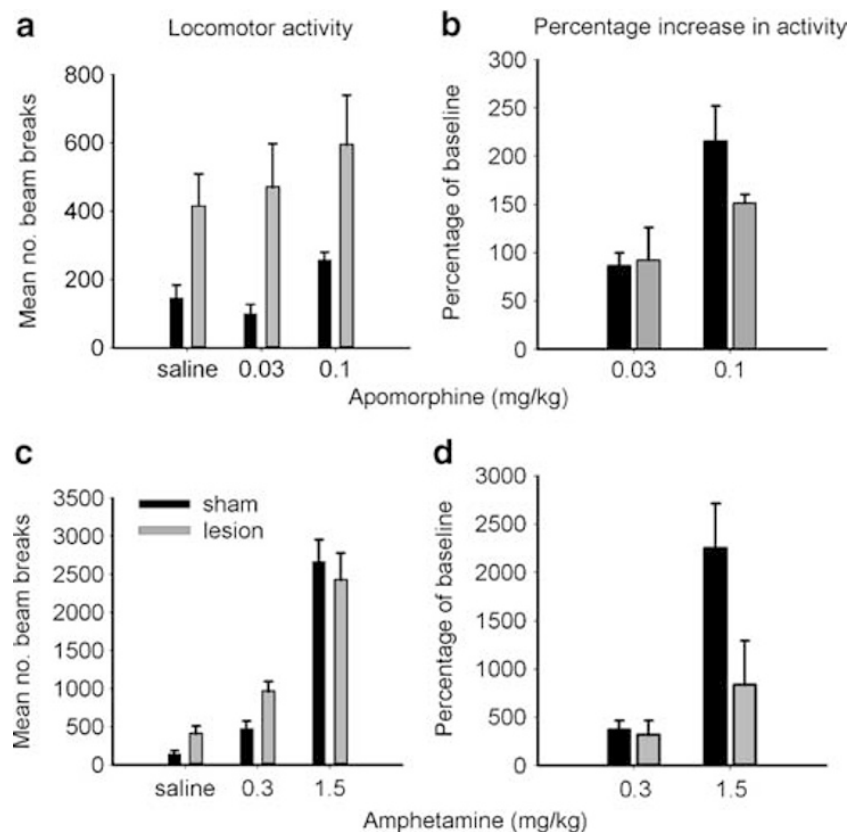

Figure 7 Effects of apomorphine (0, 0.03, $0.1 \mathrm{mg} / \mathrm{kg}$ s.c.) (a, b) and amphetamine $(0,0.3,1.5 \mathrm{mg} / \mathrm{kg}$ i.p.) (c, d) on locomotor in rats with 6-OHDA lesions of the NAC and sham-operated controls. Data shown are mean and SEM. levels observed following administration of both apomorphine and amphetamine implies that any apparent 'blockade' of the effects of higher doses of drug in animals with 6-OHDA NAC lesions was due to the fact that they were spontaneously hyperactive, and therefore may not increase their activity to the same degree following administration of stimulant drugs due to ceiling effects.

\section{Experiment 2}

Lesion analysis. In keeping with previous reports (eg Winstanley et al, 2003, 2004), i.c.v. 5,7-DHT produced an $85-90 \%$ decrease in levels of 5-HT and 5-HIAA in all regions tested (see Table 3). Levels of DA, DOPAC, and NA were unaffected.

Experiment 2.1 Effect of 8-OH-DPAT in i.c.v. 5,7-DHTlesioned rats on delay-discounting performance. Selective 5-HT depletion did not alter impulsive choice as measured by this delay-discounting paradigm in accordance with previously published data (Winstanley et al, 2003; SURGERY $\times$ LESION: $F_{1,14}=0.422$, NS; comparing data from postoperative sessions only: LESION: $\mathrm{F}_{1,14}=0.632$, NS, LESION $\times$ DELAY: $\left.\mathrm{F}_{4,56}=0.176, \mathrm{NS}\right)$. As in experiment 1.2, 8-OH-DPAT increased choice of the small immediate reward across delay (DRUG: $\mathrm{F}_{3,39}=9.415, \quad p<0.001$, Figure 8). This effect was observed in both i.c.v. 5,7-DHTlesioned animals and sham-operated controls (DRUG $\times$ LESION: $\mathrm{F}_{3,39}=1.249$, NS).

\section{DISCUSSION}

Intra-NAC 6-OHDA did not alter delay-discounting performance, nor did this manipulation block the ability of amphetamine to decrease impulsive choice, suggesting that the effects of amphetamine on this task are not dependent on the mesolimbic dopaminergic innervation of the NAC. However, 6-OHDA NAC lesions, but not global forebrain 5HT depletion, prevented the $5-\mathrm{HT}_{1 \mathrm{~A}}$ receptor agonist $8-\mathrm{OH}-$ DPAT from increasing impulsivity, an effect which was itself blocked by prior administration of the selective $5-\mathrm{HT}_{1 \mathrm{~A}}$ receptor antagonist WAY 100635. Intra-NAC 6-OHDA also attenuated 8-OH-DPAT's propensity to prevent amphetamine from decreasing impulsive choice. Hence, it would appear that the ability of 8-OH-DPAT to increase impulsivity and block the amphetamine-induced decrease in impulsivity arises through interactions between the 5-HT and DA systems. The finding that WAY 100635 augmented the effects of amphetamine on delay-discounting further reinforces the suggestion that the 5 -HT system is critically important in mediating these behavioral effects of the psychostimulant.

\section{Efficacy of the 6-OHDA NAC Lesion: Possible Functional Compensation}

In contrast to a recent report in which animals were assessed 2 weeks postoperatively (Dalley et al, 2002), animals with 6-OHDA NAC lesions in this study were spontaneously hyperactive. It has been demonstrated that, although locomotor activity is not affected 2-3 weeks after 
Table 3 Tissue Concentrations of 5-HT, 5-HIAA, DA, DOPAC, and NA in Cortical, Striatal, and Limbic Areas of I.c.v. 5,7-DHT Lesioned and Sham-Operated Rats

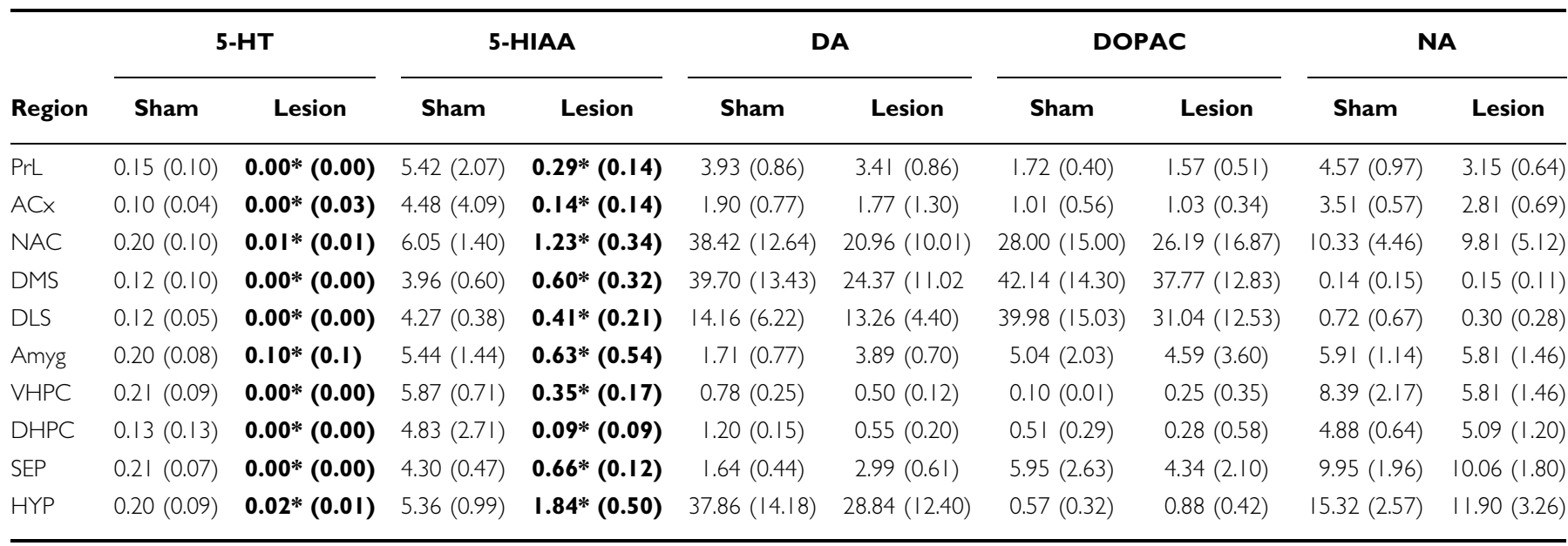

These data are averaged levels ( \pm SEM) expressed as pmol/mg to two decimal places. Levels of 5-HT and 5-HIAA in lesioned animals are highlighted in bold. *Indicates a significant difference $(p<0.05)$ between sham and lesioned groups.

PrL, prelimbic cortex; ACx, anterior cingulate; NAC, nucleus accumbens; DMS, dorsomedial striatum; DLS, dorsolateral striatum; Amyg, amygdala; VHPC, ventral hippocampus; DHPC, dorsal hippocampus; SEP, septum; HYP, hypothalamus.

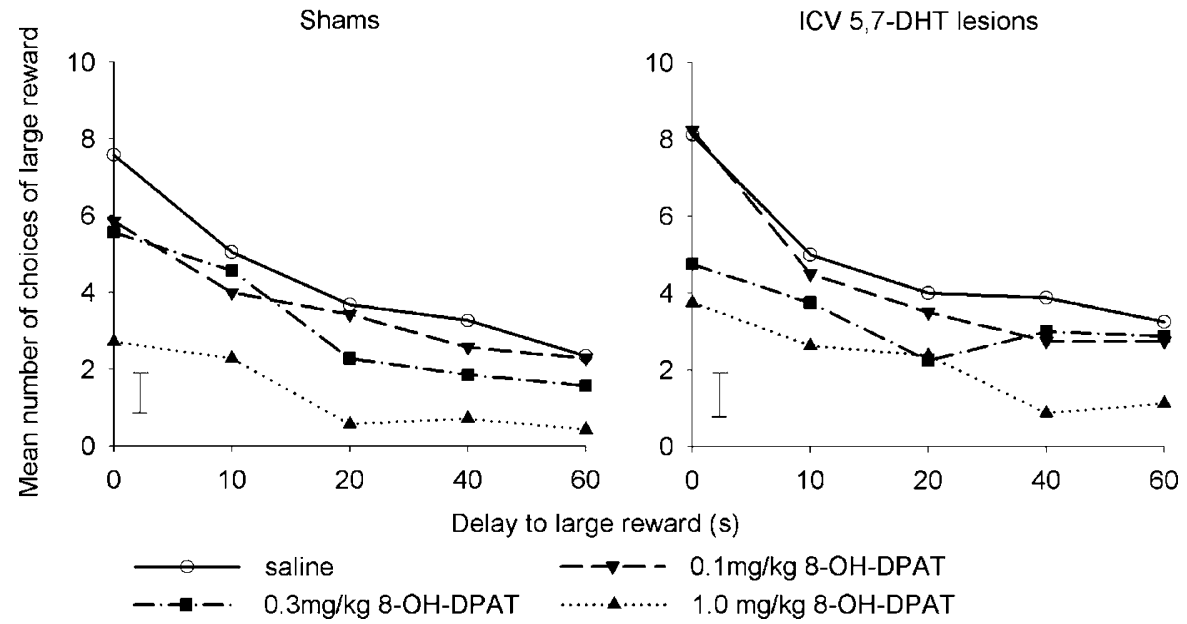

Figure 8 Effects of 8-OH-DPAT on delay-discounting performance in i.c.v. 5,7-DHT lesioned rats and sham-operated controls. Data shown are mean and SED.

6-OHDA NAC lesions, hyperactivity is observed in the same animals 2-3 months postsurgery (Parkinson et al, 2002). Similarly, although NAC 6-OHDA lesions initially block amphetamine-induced hypermotility, this locomotor response to amphetamine recovers within 3 months (Kelly et al, 1975) in keeping with the results presented here. Such temporally dependent effects of NAC 6-OHDA lesions strongly suggests that functional compensation occurs within the remaining dopaminergic and noradrenergic neurons, particularly as the lesions only reduce dopamine levels by around 70\% (Jones and Robbins, 1992). However, a similar deficit in behavioral performance (in an autoshaping paradigm) was observed in 6-OHDA NAC lesioned animals (Dalley et al, 2002), regardless of the time point at which testing occurred. Furthermore, any functional compensation that occurred in the current study was insufficient to prevent the lesion from blocking the effects of 8-OH-DPAT's effects, strongly suggesting that these mechanisms were not sufficient to fully restore normal DA and NA function within the NAC.

In keeping with a previous report using an alternative delay-discounting procedure (Richards et al, 2002), 6OHDA NAC lesions did not alter impulsive choice, despite the considerable increase in impulsivity caused by excitotoxic lesions of the NAC (Cardinal et al, 2001). However, with the exception of autoshaping (Dalley et al, 2002; Parkinson et al, 2002) and schedule-controlled drinking (Robbins and Koob, 1980), 6-OHDA lesions alone have been found to have little effect on other behavioral tasks (Taylor and Robbins, 1986; Cole and Robbins, 1989; McCullough et al, 1993; Salamone et al, 1995; Sokolowski and Salamone, 1998; Cousins et al, 1999). Furthermore, it has been 
suggested that 6-OHDA NAC lesions only show reduce response rates under reinforcement schedules which require more effortful or high levels of responding (Salamone et al, 1997, 2003).

\section{Decreasing Accumbal DA does not Block Amphetamine's Ability to Decrease Impulsive Choice}

As discussed previously, those cases in which 6-OHDA NAC lesions block the action of amphetamine strongly indicate that those effects of amphetamine are contingent on DA or NA release in the NAC. However, the fact that NAC 6OHDA lesions did not abolish the ability of amphetamine to decrease impulsive choice, and even transiently potentiated this drug effect at the lowest dose used, suggests that either the surviving $30 \%$ of neurons are capable of producing a detectable drug-induced increase in DA and NA, or that the drug's effect is not solely dependent on release of these neurotransmitters in the NAC. Recent data indicate that the 5-HT system may be involved in the anti-impulsivity effects of amphetamine (Gainetdinov et al, 1999; Winstanley et al, 2003). Although global 5-HT depletion does not alter performance of this delay-discounting task, i.c.v. 5,7-DHT lesions have been shown to attenuate the amphetamineinduced decrease in impulsive choice (Winstanley et al, 2003). Similarly, although the $D_{2}$ receptor antagonist eticlopride does not affect impulsive choice, coadministration of eticlopride with amphetamine also reduces the ability of amphetamine to decrease impulsive choice (Van Gaalen et al, 2003). Furthermore, a complete blockade of amphetamine's effects is observed in serotonergically lesioned rats, but not sham-operated controls, following coadministration of the mixed $\mathrm{D}_{1} / \mathrm{D}_{2}$ receptor antagonist cis-z-flupenthixol (Winstanley et al, 2003). These data indicate some redundancy in the roles 5-HT and DA play in controlling delay-discounting, so that manipulations which target both systems, rather than either individually, significantly affect choice behavior.

\section{5-HT : DA Interactions within the NAC Affect the Regulation of Impulsive Behavior}

Such a hypothesis may be important when considering the ability of higher doses of 8-OH-DPAT to both induce impulsive choice and block the decrease in impulsive choice caused by amphetamine in sham-operated rats. As mentioned previously, 8-OH-DPAT markedly decreases forebrain levels of 5-HT through its action at presynaptic $5-\mathrm{HT}_{1 \mathrm{~A}}$ receptors (eg Bonvento et al, 1992). However, 8-OHDPAT still induces impulsive choice in animals with i.c.v. 5,7-DHT lesions (current study), indicating that the drug is primarily acting through postsynaptic $5-\mathrm{HT}_{1 \mathrm{~A}}$ receptors. Furthermore, 8-OH-DPAT did not increase choice of the small reward in animals with 6-OHDA NAC lesions, suggesting that 8-OH-DPAT may increase impulsive choice via $5-\mathrm{HT}_{1 \mathrm{~A}}$ receptor-mediated regulation of the $\mathrm{DA}$ or NA system. Although 5-HT: NA interactions may be important in the actions of 8-OH-DPAT (see Done and Sharp, 1994; Chen and Reith, 1995), discussion of the mechanism by which 8-OH-DPAT affects impulsivity will be restricted here to its effects on DA and 5-HT, as the involvement of these neurotransmitter systems has been more firmly established in other preclinical models of impulse control (Cole and Robbins, 1987).

Whereas low doses of 8-OH-DPAT facilitate firing of DA-ergic cells, high doses depress DA-ergic neuronal activity, and these electrophysiological observations appear to parallel alterations in DA release observed in the NAC (Sinton and Fallon, 1988; Kelland et al, 1990; Arborelius et al, 1993; Chen and Reith, 1995; Ichikawa and Meltzer, 2000). $5-\mathrm{HT}_{1 \mathrm{~A}}$ receptors are located on dopaminergic cells in the ventral tegmental area (VTA) that projects to the NAC (Prisco et al, 1994; Chen and Reith, 1995; Doherty and Pickel, 2001) and are also found within the NAC itself (eg Chalmers and Watson, 1991; Barnes and Sharp, 1999). At the dose used to induce impulsive choice $(1.0 \mathrm{mg} / \mathrm{kg})$, 8 OH-DPAT would be expected to decrease DA release in the NAC, and this action of the drug may contribute to its ability to induce impulsive choice. Systemic administration of 8-OH-DPAT has also been shown to inhibit the increase in DA produced by amphetamine in the NAC, striatum, and frontal cortex in a WAY 100735-sensitive manner (Ichikawa et al, 1995; Kuroki et al, 1996); therefore, 8-OH-DPAT may antagonize the amphetamine-induced decrease in impulsive choice by preventing the psychostimulant from increasing DA in the NAC.

However, these conclusions seem to contradict the finding that decreasing DA via intra-NAC 6-OHDA has (a) no effect on impulsive choice and (b) does not block amphetamine's effects on this task. An alternative explanation is that 8-OH-DPAT has such profound effects on impulsive choice through its combined actions both directly on the 5-HT system and also indirectly on the DA system, rather than on either system individually. Hence, although neither decreasing global levels of 5-HT, nor decreasing accumbal levels of DA themselves alter impulsive choice, decreasing levels of both 5-HT and DA together may result in an increase in impulsivity. Furthermore, 8-OH-DPAT may block the amphetamine-induced reduction in impulsivity by both decreasing $5-\mathrm{HT}$ levels through $5-\mathrm{HT}_{1 \mathrm{~A}}$ autoreceptors, mimicking the ability of global 5-HT depletion to attenuate these effects of amphetamine, as well as via $5-\mathrm{HT}_{1 \mathrm{~A}}$ receptor-mediated inhibition of $\mathrm{DA}$ function. In animals with 6-OHDA NAC lesions, only the former inhibitory action of 8-OH-DPAT is present, hence only a partial blockade of amphetamine's actions was observed.

Alternatively, the differential effects of 6-OHDA NAC lesions observed here may reflect changes in the dopaminergic modulation of other areas connected to the NAC which have been shown to play a role in modulating impulsive choice. Although the differences did not reach statistical significance in this study, lesioning the dopaminergic and noradrenergic terminals in the NAC has previously been shown to decrease DA and NA levels in the PFC (Dalley et al, 2002, Jones and Robbins 1992). Both excitotoxic and dopaminergic lesions of the orbitofrontal cortex (OFC) have been shown to affect impulsive choice (Kheramin et al, 2004; Winstanley et al, 2004) and changes in the efflux of 5-HT and DA have been observed in the prelimbic and orbitofrontal cortices during performance of this delay-discounting task (Theobald et al, 2004). The effects of altering dopaminergic signalling within the limbic corticostriatal loop on impulsive decision-making may therefore deserve further investigation. 


\section{Amphetamine's Ability to Decrease Impulsive Choice is Augmented by WAY 100635}

The WAY 100635-induced potentiation of amphetamine's ability to decrease impulsive choice supports the conclusion that 8-OH-DPAT decreased this action of amphetamine via activation of $5-\mathrm{HT}_{1 \mathrm{~A}}$ receptors. Coadministration of WAY 100635 may have augmented the behavioral effects of amphetamine through blocking inhibitory $5-\mathrm{HT}_{1 \mathrm{~A}}$ autoreceptors, thereby increasing amphetamine-potentiated 5HT release. In support of this suggestion, WAY 100635 has been shown to augment increases in 5-HT and DA efflux caused by systemic administration of fluoxetine (Gobert and Millan, 1999), and increases in hippocampal and accumbal 5-HT, but not DA, caused by cocaine (Muller et al, 2002a, b). Administration of WAY 100635 directly into the dorsal raphé nucleus has also been shown to potentiate cocaine-induced hyperactivity and head bobbing (Herges and Taylor, 1999 but see Muller et al, 2002a).

In summary, these data have confirmed and extended the hypothesis that the serotonergic system is critically involved in the ability of amphetamine to decrease impulsive choice, and has highlighted the potential involvement of interactions between the DA and 5-HT systems within the NAC in mediating these effects of the psychostimulant. This form of impulsivity appears to be under the dual-regulation of both 5-HT and DA, and consequentially manipulations affecting only one of these neurotransmitter systems will have much weaker effects on impulsive behavior than those targeting both. The finding that the $5-\mathrm{HT}_{1 \mathrm{~A}}$ receptor antagonist WAY 100635 augmented the reductions in impulsive choice caused by amphetamine suggests that $5-\mathrm{HT}_{1 \mathrm{~A}}$ receptor antagonists may provide a useful adjunct to more traditional pharmacotherapy for impulse control disorders such as ADHD. Improved understanding of the nature of 5$\mathrm{HT}$ :DA interactions, both globally and at the level of individual receptors, may further elucidate the neurochemical basis of impulsive behavior.

\section{ACKNOWLEDGEMENTS}

This work was supported by a Wellcome Trust Programme grant and completed within the MRC Centre for Behavioral and Clinical Neuroscience. CAW was supported by an MRC Studentship.

\section{REFERENCES}

Ahlenius S, Hillegaart V, Wijkstrom A (1990). Increased dopamine turnover in the ventral striatum by $8-\mathrm{OH}-\mathrm{DPAT}$ administration in the rat. J Pharm Pharmacol 42: 285-288.

Alexander GE, Crutcher MD, DeLong MR (1990). Basal gangliathalamocortical circuits - parallel substrates for motor, oculomotor, prefrontal and limbic functions. Prog Brain Res 85: 119-146.

Arborelius L, Nomikos GG, Hacksell U, Svensson TH (1993). (R)8-Oh-Dpat preferentially increases dopamine release in rat medial prefrontal cortex. Acta Physiol Scand 148: 465-466.

Balcioglu A, Zhang K, Tarazi FI (2003). Dopamine depletion abolishes apomorphine- and amphetamine-induced increases in extracellular serotonin levels in the striatum of conscious rats: a microdialysis study. Neuroscience 119: 1045-1053.

Barnes NM, Sharp T (1999). A review of central 5-HT receptors and their function. Neuropharmacology 38: 1083-1152.
Bizot JC, Le Bihan C, Puech AJ, Hamon M, Thiebot MH (1999). Serotonin and tolerance to delay of reward in rats. Psychopharmacology 146: 400-412.

Bjorkland A, Baumgarten HD, Rensch A (1975). 5,7-Dihydroxytryptamine: improvement of its selectivity for serotonin neurons in the CNS by treatment with desipramine. J Neurochem 24: 833-835.

Bonvento G, Scatton B, Claustre Y, Rouquier L (1992). Effect of local injection of 8-OH-DPAT into the dorsal or median raphe nuclei on extracellular levels of serotonin in serotonergic projection areas in the rat brain. Neurosci Lett 137: 101-104.

Burns LH, Robbins TW, Everitt BJ (1993). Differential effects of excitotoxic lesions of the basolateral amygdala, ventral subiculum and prefrontal cortex on responding with conditioned reinforcement and locomotor activity potentiated by intraaccumbens infusions of amphetamine. Behav Brain Res 55: 167-183.

Cador M, Taylor JR, Robbins TW (1991). Potentiation of the effects of reward-related stimuli by dopaminergic-dependent mechanisms in the nucleus-accumbens. Psychopharmacology 104: 377-385.

Campbell A, Villavincencio AT, Yeghiayan SK, Balikian R, Baldessarini RJ (1997). Mapping of locomotor behavioral arousal induced by microinjections of dopamine within nucleus accumbens septi of rat forebrain. Brain Res 771: 55-62.

Cardinal RN, Parkinson JA, Lachenal G, Halkerston KM, Rudarakanchana N, Hall J et al (2002). Effects of selective excitotoxic lesions of the nucleus accumbens core, anterior cingulate cortex, and central nucleus of the amygdala on autoshaping performance in rats. Behav Neurosci 116: 533-567. Cardinal RN, Pennicott DR, Sugathapala CL, Robbins TW, Everitt BJ (2001). Impulsive choice induced in rats by lesions of the nucleus accumbens core. Science 292: 2499-2501.

Cardinal RN, Robbins TW, Everitt BJ (2000). The effects of $d$-amphetamine, chlordiazepoxide, alpha-flupenthixol and behavioral manipulations on choice of signalled and unsignalled delayed reinforcement in rats. Psychopharmacology 152: 362-375.

Carey MP, Diewald LM, Esposito FJ, Pellicano MP, Carnevale UAG, Sergeant JA et al (1998). Differential distribution, affinity and plasticity of dopamine D-1 and D-2 receptors in the target sites of the mesolimbic system in an animal model of ADHD. Behav Brain Res 94: 173-185.

Carr GD, White N (1987). Effects of systemic and intracranial amphetamine injections on behavior in the open field: a detailed analysis. Pharmacol Biochem Behav 27: 113-122.

Chalmers DT, Watson SJ (1991). Comparative anatomical distribution of 5-HT1A receptor mRNA and 5-HT1A binding in rat brain - a combined in situ hybridisation/in vitro receptor autoradiographic study. Brain Res 561: 51-60.

Chen N-H, Reith MEA (1995). Monoamine interactions meausured by microdialysis in the ventral tegmental area of rats treated systemically with (8-hydroxy-2-(di-n-propylamino)-tetralin. J Neurochem 64: 1585-1597.

Cole BJ, Robbins TW (1987). Amphetamine impairs the discriminative performance of rats with dorsal noradrenergic bundle lesions on a 5-choice serial reaction time task: new evidence for central dopaminergic-noradrenergic interactions. Psychopharmacology 91: 458-466.

Cole BJ, Robbins TW (1989). Effects of 6-hydroxydopamine lesions of the nucleus accumbens septi on performance of a 5 -choice serial reaction time task in rats-implications for theories of selective attention and arousal. Behav Brain Res 33: 165-179.

Cousins MS, Trevitt J, Atherton A, Salamone JD (1999). Differential behavioral functions of dopamine in nucleus accumbens and venterolateral striatum: a microdialysis and behavioral investigation. Neuroscience 91: 925-934. 
Dalley JW, Chudasama Y, Theobald DE, Pettifer CL, Fletcher CM, Robbins TW (2002). Nucleus accumbens dopamine and discriminated approach learning: interactive effects of 6-hydroxydopamine lesions and systemic apomorphine administration. Psychopharmacology 161: 425-433.

De La Garza R, Cunningham KA (2000). The effects of the 5 -hydroxytryptamine ${ }_{1 a}$ agonist 8-hydroxy-2-(di-n-propylamino) tetralin on spontaneous activity, cocaine-induced hyperactivity and behavioral sensitization: a microanalysis of locomotor activity. J Pharmacol Exp Ther 292: 610-617.

Doherty MD, Pickel VM (2001). Targeting of serotonin 1A receptors to dopaminergic neuron within the parabrachial subdivision of the ventral tegmental area. J Comp Neurol 433: 390-400.

Done CJ, Sharp T (1994). Biochemical evidence for the regulation of central noradrenergic activity by $5-\mathrm{HT}_{1 \mathrm{~A}}$ and $5-\mathrm{HT}_{2}$ receptors: microdialysis studies in the awake and anaesthetised rat. Neuropharmacology 33: 411-421.

Evenden JL, Ryan CN (1996). The pharmacology of impulsive behaviour in rats: the effects of drugs on response choice with varying delays of reinforcement. Psychopharmacology 128: 161-170.

Evenden JL, Ryan CN (1999). The pharmacology of impulsive behaviour in rats: VI the effects of ethanol and selective serotonergic drugs on response choice with varying delays of reinforcement. Psychopharmacology 146: 413-421.

Gainetdinov RR, Wetsel WC, Jones SR, Levin ED, Jaber M, Caron MG (1999). Role of serotonin in the paradoxical calming effect of psychostimulants on hyperactivity. Science 283: 397-401.

Gobert A, Millan MJ (1999). Modulation of dialysate levels of dopamine, noradrenaline, and serotonin $(5-\mathrm{HT})$ in the frontal cortex of freely-moving rats by (-)-pindolol and in association with 5-HT reuptake alone and in association with 5-HT reuptake inhibtors: comparative roles of beta-adrenergic, $5-\mathrm{HT}_{1 \mathrm{~A}}$, and 5- $\mathrm{HT}_{1 \mathrm{~B}}$ receptors. Neuropsychopharmacology 21: 268-284.

Herges S, Taylor DA (1999). Modulation of cocaine-induced locomotor activity, rears and head-bobs by application of WAY100635 into the dorsal and median raphe nuclei of the rat. Naunyn-Schmiedebergs Arch Pharmacol 360: 129-134.

Ichikawa J, Kuroki T, Kitchen MT, Meltzer HY (1995). R(+)-8-OHDPAT, a $5-\mathrm{HT}_{1 \mathrm{~A}}$ receptor agonist, inhibits amphetamineinduced dopamine release in rat striatum and nucleus accumbens. Eur J Pharmacol 287: 179-184.

Ichikawa J, Meltzer HY (2000). The effect of serotonin (1A) receptor agonism on antipsychotic drug-induced dopamine release in rat striatum and nucleus accumbens. Brain Res 858: 252-263.

Jones GH, Robbins TW (1992). Differential effects of mesocortical, mesolimbic, and mesostriatal dopamine depletion on spontaneous, conditioned and drig-induced locomotor activity. Pharmacol Biochem Behav 43: 887-895.

Kelland MD, Freeman AS, Chiodo LA (1990). Serotonergic afferent regulation of the basic physiology and pharmacological responsiveness of nigrostriatal dopamine neurons. J Pharmacol Exp Ther 253: 803-811.

Kelly PH, Seviour PW, Iversen SD (1975). Amphetamine and apomorphine responses in the rat following 6-OHDA lesions of the nucleus accumbens septi and corpus striatum. Brain Res 94: 507-522.

Kheramin S, Body S, Ho MY, Velazquez-Martinez DN, Bradshaw CM, Szabadi E et al (2004). Effects of orbital prefrontal cortex dopamine depletion on inter-temporal choice: a quantitative analysis. Psychopharmacology 175: 206-214.

Koob G, Riley ST, Smith SC, Robbins TW (1978). Effects of 6-hydroxydopamine lesions of the nucleus accumbens septi and olfactory tubercle on feeding, locomotor activity and amphetamine anorexia in the rat. J Comp Physiol Psychol 92: 917-927.
Kuczenski R, Segal DS (1989). Concomitant characterisation of behavioral and striatal neurotransmitter response to amphetamine using in vivo microdialysis. J Neurosci 9: 2051-2065.

Kuczenski R, Segal DS (1995). Hippocampus norepinephrine, caudate dopamine and serotonin, and behavioral responses to the stereoisomers of amphetamine and methamphetamine. J Neurosci 15: 1306-1317.

Kuczenski R, Segal DS, Leith NJ, Applegate CD (1987). Effects of amphetamine, methylphenidate, and apomorphine on regional brain serotonin and 5-hydroxyindole acetic acid. Psychopharmacology 93: 329-335.

Kuroki T, Ichikawa J, Dai J, Meltzer HY (1996). $R(+)-8-O H-D P A T$, a 5-HT1A receptor agonist, inhibits amphetamine-induced serotonin and dopamine release in rat medial prefrontal cortex. Brain Res 743: 357-361.

Lyness WH, Friedle NM, Moore KE (1979). Destruction of dopaminergic nerve terminals in nucleus accumbens: effects on $d$-amphetamine self-administration. Pharmacol Biochem Behav 11: 553-556.

McCullough LD, Cousins MS, Salamone JD (1993). The role of nucleus accumbens dopamine in responding on a continuous reinforcement operant schedule: a neurochemical and behavioral study. Pharmacol Biochem Behav 46: 581-586.

Mogenson GJ, Jones DL, Yim CY (1980). From motivation to action: functional interface between the limbic system and the motor system. Prog Neurobiol 14: 69-97.

Muller CP, Carey RJ, De Souza Silva MA, Jocham G, Huston JP (2002a). Cocaine increases serotonergic activity in the hippocampus and nucleus accumbens in vivo: $5-\mathrm{HT}_{1 \mathrm{~A}}$-receptor antagonism blocks behavioral but potentiates serotonergic activation. Synapse 45: 67-77.

Muller CP, De Souza Silva MA, DePalma G, Tomaz C, Carey RJ, Huston JP (2002b). The selective serotonin(1A)-receptor antagonist WAY 100635 blocks behavioral stimulating effects of cocaine but not ventral striatal dopamine increase. Behav Brain Res 134: 337-346.

Papa M, Diewald L, Carey MP, Esposito FJ, Carnevale UAG, Sadile AG (2002). A rostro-caudal dissociation in the dorsal and ventral striatum of the juvenile SHR suggests an anterior hypo- and a posterior hyperfunctioning mesocorticolimbic system. Behav Brain Res 130: 171-179.

Papa M, Sergeant JA, Sadile AG (1997). Differential expression of transcription factors in the accumbens of an animal model of ADHD. NeuroReport 8: 1607-1612.

Papa M, Sergeant JA, Sadile AG (1998). Reduced transduction mechanisms in the anterior accumbal interface of an animal model of attention-deficit hyperactivity disorder. Behav Brain Res 94: 187-195.

Parkinson JA, Dalley JW, Cardinal RN, Bamford A, Fehnert B, Lachenal G et al (2002). Nucleus accumbens dopamine depletion impairs both acquisition and performance of appetitive Pavlovian approach behaviour: implications for mesoaccumbens dopamine function. Behav Brain Res 137: 149-163.

Parkinson JA, Robbins TW, Everitt BJ (1999). Selective excitotoxic lesions of the nucleus accumbens core and shell differentially affect aversive Pavlovian conditioning to discrete and contextual cues. Psychobiology 27: 256-266.

Pijnenburg AJ, Honig WM, van der Jeyden JA, Van Rossum JM (1976). Effects of chemical stimulation of the mesolimbic dopamine system upon locomotor activity. Eur J Pharmacol 35: $45-58$.

Prisco S, Paganonne S, Esposito E (1994). Serotonin-dopamine interaction in the rat ventral tegmental areas: an electrophysiological study in vivo. J Pharmacol Exp Ther 271: 83-90.

Przegalinski E, Filip M (1997). Stimulation of serotonin (5-HT)1A receptors attenuates the locomotor, but not the discriminative, effects of amphetamine and cocaine in rats. Behav Pharmacol 8: 699-706. 
Richards JB, Ishiwari K, Hauskneckt K, Salamone JD (2002). Effects of nucleus accumbens dopamine depletion on the value of delayed rewards in rats. In: Abstract Viewer/Itinerary Planner. On-line: Society for Neuroscience: Washington, DC.

Robbins TW, Koob GF (1980). Selective disruption of displacement behaviour by lesions of the mesolimbic dopamine system. Nature 285: 409-412.

Robbins TW, Roberts DC, Koob G (1983). Effects of $d$-amphetamine and apomorphine upon operant behavior and schedule-induced licking in rats with 6-hydroxydopamineinduced lesions of the nucleus accumbens. J Pharmacol Exp Ther 224: 662-673.

Salamone JD, Correa M, Mingote S, Weber SM (2003). Nucleus accumbens dopamine and the regulation of effort in foodseeking behavior: implications for studies of natural motivation, psychiatry, and drug abuse. J Pharmacol Exp Ther 305: 1-8.

Salamone JD, Cousins MS, Snyder BJ (1997). Behavioral functions of nucleus accumbens dopamine: empirical and conceptual problems with the anhedonia hypothesis. Neurosci Biobehav Rev 21:341-359.

Salamone JD, Kurth P, McCullough LD, Sokolowski JD (1995). The effects of nucleus accumbens dopamine depletions on continuously reinforced operant responding: contrasts with the effects of extinction. Pharmacol Biochem Behav 50: 437-443.

Sinton CM, Fallon SL (1988). Electrophysiological evidence for a functional differentiation between subtypes of the $5-\mathrm{HT}_{1}$ receptor. Eur J Pharmacol 157: 173-181.

Sokolowski JD, Salamone JD (1998). The role of nucleus accumbens dopamine in lever pressing and response allocation: effects of 6-OHDA injected into core and dorsomedial shell. Pharmacol Biochem Behav 59: 557-566.

Solanto MV (1998). Neuropsychopharmacological mechanisms of stimulant drug action in attention-deficit hyperactivity disorder: a review and integration. Behav Brain Res 94: 127-152.

Spyraki C, Fibiger HC, Phillips AG (1982). Dopaminergic substrates of amphetamine-induced place preference conditioning. Brain Res 253: 185-193.
Taylor JR, Horger BA (1999). Enhanced responding for conditioned reward produced by intra-accumbens amphetamine is potentiated after cocaine sensitisation. Psychopharmacology 142: $31-40$.

Taylor JR, Robbins TW (1984). Enhanced behavioral control by conditioned reinforcers following microinjections of $D$-amphetamine into the nucleus accumbens. Psychopharmacology 84: 405-412.

Taylor JR, Robbins TW (1986). 6-Hydroxydopamine lesions of the nucleus accumbens, but not of the caudate nucleus, attenuate enhanced responding with reward-related stimuli produced by intraaccumbens $D$-amphetamine. Psychopharmacology 90: 390-397.

Theobald DEH, Winstanley CA, Dalley JW, Robbins TW (2004). Performance of a task measuring impulsive choice alters monoamine function in rat frontal cortex. In: Program No. 940.1 Society for Neuroscience Abstract Viewer/Itinerary Planner. On-line, Society for Neuroscience: Washington, DC.

Van Gaalen MM, Van Koten RC, Schoffelmeer ANM, Vanderschuren LJM (2003). Dopaminergic involvement in cognitive impulsivity. In: Program No. 757.6 Society for Neuroscience Abstract Viewer/Itinerary Planner. On-line, Society for Neuroscience: Washington, DC.

Winstanley CA, Theobald DE, Cardinal RN, Robbins TW (2004). Contrasting roles for basolateral amygdala and orbitofrontal cortex in impulsive choice. J Neurosci 24: 4718-4722.

Winstanley CA, Theobald DE, Dalley JW, Robbins TW (2003). Global 5-HT depletion attenuates the ability of amphetamine to decrease impulsive choice in rats. Psychopharmacology 170: 320-331.

Winstanley CA, Theobald DE, Dalley JW, Robbins TW (2004). Fractionating impulsivity: contrasting effects of central 5-HT depletion on different measures of impulsive behavior. Neuropsychopharmacology 29: 1331-1343 (originally published online 9 February 2004 at: http://www.acnp.org/citations/ NPP02090403391/default.pdf). 